\title{
LA APELACIÓN FISCAL EN LA LEGISLACIÓN DE CONSTANTINO
}

\author{
Alfonso AGUDo RUIZ \\ CATEDRÁTiCo DE DeReCHo Romano \\ UNIVERSIDAD DE LA RIOJA
}

RESUMEN: El presente estudio tiene por objeto analizar las dos epistulae, dirigidas al rationalis urbis Romae y al praefectus urbis, donde Constantino admite con carácter general la apelación fiscal, sin limitación alguna, centrando su atención en acelerar los trámites de dichos juicios a fin de que no resultase perjudicado el interés público.

Palabras Clave: Constantino, apelación fiscal

ABSTRACT: The present investigation analyzes the two epistulae addressed to the rationalis urbis Romae and the praefectus urbi, in which Constantine always admitis the fiscal appeal without limits and pays attention to the acceleration of the procedures of those trials, so that the public interest was not damaged.

KEYwORDS: Constantine, fiscal appeal

GAUDEMET $^{\mathrm{I}}$ afirma que las transformaciones de la organización judicial y los cambios de procedimiento, iniciados desde hacía más de un siglo, necesitan al comienzo del siglo IV, cuando Constantino emprende la implantación de un nuevo régimen político y administrativo, una reglamentación jurídica adecuada. Esta voluntad reformista del emperador cristiano, viene acreditada, en opinión del citado autor ${ }^{2}$, por el elevado número de constituciones emitidas entre el I de diciembre del 3I2 y el 2I mayo del 337, recordemos que Constantino muere repentinamente después de una breve enfemedad el 22 de mayo del 337, un total de 276 disposiciones recogidas en el Código de Teodosio, a las que habría que añadir otras 56 que figuran exclusivamente en el Código de Justiniano.

\footnotetext{
'GAUDEMET, «Constitutions constantiniennes relatives à l'appel», en ZSS, 98, I981, págs. 47 y SS.

${ }^{2}$ GAUDEMET, «Les constitutions constantiniennes du Code Théodosien», en Atti dell'Accademia Romanistica Costantiniana, V, Milano, I983, pág. I36, nt. 4; 137; 139. En págs. I54 y ss., recoge en el Anexo, 56 constituciones constantinianas que figuran en el Código de Justiniano y no así en el Código de Teodosio. HAYASHI, «L'appello e altri mezzi processuali sotto l'Imperatore Costantino I», en Atti dell'Accademia Romanistica Costantiniana. XI Convegno Internazionale in onore di Felix B.J. Wubbe, Napoli I996, pág. 70, habla de casi 400 constituciones pertenecientes a nuestro emperador, de las que 36 se refieren a la apelación.
} 
De estas 332 constituciones, 26 se refieren a la apelación, lo que en opinión de algunos autores ${ }^{3}$, hace pensar en una reordenación orgánica de la institución, dentro de su amplio programa de reorganziación del sistema judicial.

$\mathrm{HAYASHI}^{4}$, matiza que esta posición de Constantino solo puede ser valorada en su justa medida después de haber analizado todos los temas jurídicos por los que él se interesó, y comparar sus resultados con aquellos de sus predecesores y de sus sucesores.

En opinión de PERGAMI 5 , aun siendo innegable el interés de Constantino por los problemas del proceso de apelación, sobre todo en los primeros tiempos de su gobierno, como lo atestigua el elevado número de disposiciones de las que figura como autor en el Código Teodosiano y que en parte han pasado al Código de Justiniano, es discutible que tan abundante legislación responda a un plan orgánico y sistemático reformador del régimen del instituto. En este sentido, la mayor parte de las disposiciones que leemos en los Códigos no tienen propiamente carácter legislativo, no lo tienen formalmente, salvo el único edicto ad universos provinciales emanado en el 33I (C. Th. II. 30.I6; II. 30. I7; II. 34. I), y tampoco lo tienen sustancialmente, están privados de aquel carácter de generalidad que se puede atribuir a textos dirigidos al Senado, a los miembros del aparato central del gobierno o a funcionarios investidos de altas competencias administrativas como los prefectos del pretorio. Por el contrario, son a menudo instrucciones dirigidas a funcionarios periféricos de rango poco elevado, como gobernadores provinciales o rationales, y referidos a situaciones o comportamientos particulares. Lo cual no significa que en el marco del Código Teodosiano, estos textos no hayan alcanzado un valor normativo; pero para una correcta valoración de la obra de Constantino es necesario preguntarse cuáles eran su significado y su amplitud originaria en las intenciones del emperador y en la obra del aparato burocrático en el que estos textos venían elaborados. La respuesta a estas preguntas no es, naturalmente, ni fácil ni segura, sobre todo por el estado en el que los textos han sido conservados en los Códigos, en forma fragmentaria, privados de motivaciones que, como es sabido, adornaban los procedimientos imperiales, con graves imprecisiones y lagunas en la indicación de los lugares, de las personas o de las fechas, por lo que la reconstrucción de su sentido originario resulta sumamente difícil. Añade el citado autor ${ }^{6}$ que otro motivo de duda lo constituye el hecho de que buena parte de la producción constantiniana en materia de apelación es anterior al 324, año de la reunificación del Imperio con la derrota y eliminación de Licinio. Lo cual plantea dudas sobre la vigencia de su legislación en todas las partes del Imperio. Por último, queda por aclarar si la cancillería constantiniana conocía y asumía el edicto de Diocleciano del 294, lo cual parece contradicho por algunas disposiciones constantinianas. Por ello es necesario proceder con la máxima cautela antes de asumir que dichas disposiciones constituyen partes orgánicas y sistemáticas de un procedimiento de reorganización claro y definido.

\footnotetext{
${ }^{3}$ Jones, «Il Tardo Impero Romano (284-602), II», trad. ital. Petretti, Milano, I974, pág. 697; De MarTino, «Storia della costituzione romana, V», Napoli, I975, pág. 487.

${ }^{4}$ HAYASHI, «L'appello e altri mezzi processuali», cit., pág. 69.

${ }^{5}$ Pergami, «L'appello nella legislazione del tardo Impero», Milano, 2000, pág. 45 y ss.

${ }^{6}$ Pergami, «L'appello...», cit., 48 ss.
} 
A nuestros efectos, como afirma PERGAMI', ninguna norma, de entre aquellas atribuidas a Constantino, está específicamente dedicada a regular detalladamente el proceso de la apelación contra una sentencia que haya decidido una controversia de naturaleza fiscal, tributaria o relativa a la res privata principis. En efecto, como veremos, Constantino dedica escasa atención a la apelación fiscal ${ }^{8}$, reducida a dos disposiciones legislativas, en ambos casos dos epistulae, dirigidas al rationalis urbis Romae y al praefectus urbis, donde admite con carácter general la apelación en esta materia, sin limitación alguna, centrando su atención en acelerar los trámites de dichos juicios a fin de que no resultase perjudicado el interés público?.

En esta línea se enmarca la primera disposición de Constantino, una epistula que según la inscriptio del Código Teodosiano es emitida el 3I de julio del $327^{\mathrm{II}}$, dirigida al rationalis urbis Romae Victor, en materia de deudas fiscales, que como afirma PERGAMI ${ }^{\mathrm{I}}$, pone de relieve la sensibilidad de Constantino por la razonable duración de los procesos de naturaleza fiscal, para evitar maniobras dilatorias que puedan ser realizadas por los apelantes -appellatoris ${ }^{\mathrm{r}}$ - con grave daño para los intereses fiscales:

C. Th. II. 30. I4: Idem (Imp. Constantinus) A. Victori rationali urb(is) Rom(ae). Quoniam nonnulli fisci debitoris, cum iussi fuerint debitam summam exsolvere, interpositio provocationis auxilio vim executionis eludunt nec iam opinionis exemplum nec refutatorias preces curant petere vel offerre, placuit, ut, si intra dies complendis sollemnitatibus praestitutos ad facienda haec appellatoris cura defuerit, deserta ab eo provocatio aestimetur moxque debitum exigatur. Dat. prid. Kal Aug. Constantino et Maximo conss.

Como observa PERGAMI ${ }^{\text {I4 }}$, la epistula permite afirmar que la apelación fiscal era admitida, no solo cuando ha sido pronunciada una sentencia en sede contenciosa, sino también frente a un mandamiento de pago, en la que se prevé y se regula la apelación que

\footnotetext{
${ }^{7}$ PeRgAmi, «Interesse pubblico e tutela del privato nella legislazione tardoimperiale in materia di processo fiscale», en Atti dell'Accademia Romanistica Costantiniana. XII Convegno Internazionale in onore a Manlio Sargenti, Milano I998, pág. 4I4, «Studi di didiritto romano tardoantico», Torino 20II, pág. I95.

${ }^{8}$ En este sentido, PAdOA SCHIOppa, «Ricerche sull'appello in diritto intermedio, I», Milano I967, 69.

${ }^{9}$ En este sentido, PAdoA SCHIOpPA, «Ricerche sull'appello...», cit., 69; LiTEWSKI, «Ricerche sull'appello (Rec. Padoa Schioppa, Ricerche sull'appello in diritto intermedio), en Labeo, I9, I973, pág. 224; PerGAMI, «L'appello...», cit., pág. I35; I4I; 316.

${ }^{10}$ Así la califica Spagnuolo Vigorita, «Aspetti e problema del proceso fiscale in età costantiniana», en Atti dell'Accademia Romanistica Costantiniana. XI Convegno Internazionale in onore di F. Wubbe, Napoli, I996, pág. I6I, para quien la constitución se ocupa de la apelación consultationum more, que parece ser con Constantino el instrumento usual de impugnación en materia fiscal.
}

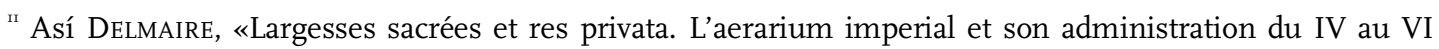
siècle», Paris-Roma, I989, pág. I83; I85; SpaGnuolo VigoRITA, «Aspetti e problema del proceso fiscale...», cit., pág. I6I. Cfr. HAYASHI, «L’appello e altri mezzi processuali», cit., pág. 78, duda del día de emisión: 25 ó 3І de julio.

${ }^{12}$ Pergami, «Interesse pubblico e tutela del privato», cit., pág. 4I4. «Studi...», cit., pág. I95; ID. «L'appello...», cit., pág. 269; 464; ID. «Sulla ragionevole durata del processo nella legislazione tardoimperiale», en Scriti per Gennaro Franciosi, III, Napoli, 2007, pág. 2066. En el mismo sentido, con anterioridad PAdOA SCHIOPPA, «Ricerche sull'appello...», cit., pág. 69 nt. 88.

\footnotetext{
${ }^{13}$ Pergami, «L'appello nella legislazione del tardo Impero», cit., pág. 269 nt. I.

${ }^{14}$ Pergami, «L’appello nella legislazione del tardo Impero», cit., pág. 243.
} 
los deudores fiscales pueden interponer frente a las cantidades que deben abonar al fisco. En efecto, como afirma el citado autor ${ }^{15}$, Constantino censura el comportamiento dilatorio de los debitores fisci que, después de haber impugnado, no la sentencia, sino el mandamiento de pago emitido por los órganos financieros competentes- iussi fuerint debitam summam exsolvere-, en este caso el rationalis urbis Romae, destinatario de la constitución, omiten pedir el exemplum de la opinio y de offerre los preces refutatoriae, beneficiándose así, al paralizar la acción ejecutiva, del efecto suspensivo de la apelación.

Constantino establece que se considerará decaído en la apelación al deudor fiscal que, después de haber interpuesto la apelación - interpositio provocationis auxilio-, no cumple en los términos establecidos las formalidades prescritas para la continuación del juicio: la petición de la opinio al juez a quo, es decir, la opinión que le merece la impugnación, antes de transmitir las actuaciones al tribunal superior, que según algunos autores sería el praefectus urbis Romae $e^{16}$ y el depósito del escrito de las observaciones de las partes sobre la opinión emitida por el juez inferior ${ }^{\text {r7 }}$ - preces o libelli refutatoriae-, y en consecuencia es constreñido al pago de la deuda fijada por el rationalis.

La epistula no especifica el plazo dentro del cual deben cumplirse por parte de los debitores fisci las solemnidades establecidas en la disposición -si intra dies complendis sollemnitatibus praestitutos-, a fin de que la provocatio interpuesta por éstos no sea declarada dilatoria y nula. MOMMSEN ${ }^{18}$, observa que en el Scholia Vaticana XIIII, referido a la citada disposición constantiniana, viene precisado el plazo que ésta había fijado para el cumplimiento de las mencionadas solemnidades, veinte días: arcet debitorem fisci per adpellationem debiti executionem eludere. Iubet ut, si suam praesentiam intra $X X$ dies non praesentaverit, eius appellatio vacuetur. Añade el ilustre romanista germano que adscripsit ad vocabulum 4 praestitutos manus diversa: id est intra XX dies.

DE DOMINICIS ${ }^{19}$, con base en la observación de Mommsen, considera que el escoliasta occidental habría tomado el término de veinte días del texto originario de la

\footnotetext{
${ }^{15}$ Pergami, «L'appello nella legislazione del tardo Impero, cit., pág. 99; I36 nt. I49; 243; 464; ID., «Appellatio more consultationis», en SDHI, pág. 69; 2003, pág. I7I. Studi...», cit., pág. 266; ID., «Sulla ragionevole durata del processo», cit., pág. 2067. En el mismo sentido, DE MARINI AvonZo, «La giustizia nelle province agli inizi del Basso Impero, II. L’organizzazione giudiziaria di Costantino», en Studi Urbinati, pág. 3I, I962-63, pág. 2I8 nt. I62; PADOA Schioppa, «Ricerche sull'appello», cit., pág. 69 nt. 88. Cfr. Delmaire, «Largesses sacrées et res privata», cit., pág. 203, para quien se trata de una apelación de sentencia definitiva.

${ }^{16}$ Spagnuolo Vigorita, «Aspetti e problema del proceso fiscale», cit., pág. i63; Pergami, L’appello...», cit., pág. 420. Cfr. VinCENTI, «Ante sententiam appellari potest. Contributo allo studio dell'appellabilità delle sentenze interlocutorie nel processo romano», Padova, I986, pág. 83 y nt. I44 y DELMAIRE, «Largesses sacrées et res privata», cit., pág. 85; I96; 203, quienes consideran que el tribunal competente sería el del comes rerum privatarum.
}

${ }^{17}$ Sobre la opinio y los preces o libelli refutatoriae, vid., PERGAMI, «L’appello...», cit., pág. 88 y SS.; IOI s.; ID., Sulla ragionevole durata del processo», cit., pág. 2066 nt. 8. Cfr. DelmAiRE, «Largesses sacrées et res privata», cit., pág. 85 y Spagnuolo Vigorita, «Aspetti e problema del proceso fiscale», cit., pág. i6ı, consideran que opinionis exemplum se refiere a la copia de la sentencia del juez.

${ }^{18}$ MommSEn, «Theodosiani libri XVI, cum constitutionibus Sirmondianis, I», Germany, I990, pág. 628. En el mismo sentido, Delmaire, «Largesses sacrées et res privata», cit., pág. 85; 203.

19 De Dominicis, «Registro delle alterazioni (glossemi ed interpolazioni) nelle costituzioni del Codice Teodosiano e nelle Novelle Posteodosiane segnalate dalla critica», en BIDR, 57-58, I953, pág. 429 nt. 4. 
constitución. Si ello es así, podría deducirse que la supresión del plazo de los veinte días, que originariamente debía estar establecido en la constitución, ha sido obra de los compiladores teodosianos, quizá con la finalidad de adecuar la norma procesal fijada en la constitución a los distintos usos vigentes en la praxis oriental; en efecto, la constitución en su redacción original iba dirigida a Italia, concretamente al Rationalis Urbis Romae, Victor.

Como afirma PERGAMi ${ }^{20}$, corresponde al juez a quo, en este caso el rationalis urbis Romae, destinatario de la epistula, con jurisdicción en materia de deudas fiscales de la administración financiera sobre la Italia suburbicaria a excepción de las islas ${ }^{2 \mathrm{I}}$, determinar si se han cumplido en forma y tiempo todos los requisitos integrados en la expresión «solemnia appellationis».

Por último, la epistula califica el ejercicio de la apelación como auxilium provocationis, calificación que se repetirá en otra epistula de Constancio del año 355 colocada por los compiladores teodosianos en C. Th. II. 36. I2, lo que plantea la cuestión de si la posibilidad de proponer la apelación es concebida como un verdadero y propio derecho subjetivo o no. En opinión de PERGAMI ${ }^{22}$, dicha formulación revela la consideración de la apelación como un instrumento fundado sobre un reconocimiento discrecional. Esta concepción se remonta probablemente a los orígenes del instituto, nacido como un recurso al emperador y cuya intervención asumía necesariamente la naturaleza de acto discrecional. Tal concepción persiste en la mentalidad jurídica de la época tardía, como lo prueba, de un lado, el obstinado comportamiento de los jueces, ampliamente combatido por la legislación imperial, a obstaculizar o limitar el acceso de los litigantes al ejercicio de la apelación y, de otro lado, los amplios poderes atribuidos al juez a quo, característicos del procedimiento de segundo grado, que demuestran la subsistencia de un margen de poderes discrecionales que caracteriza todavía la apelación de la época postclásica.

La segunda disposición de Constantino reguladora de la apelación fiscal, que se inscribe en la misma línea que la constitución del 327, es otra epistula ${ }^{23}$ dirigida al praefectus urbi Romae Anicio Juliano, emitida en Serdica o Sardica el ig de junio y publicada en Roma el 27 de julio del $329^{24}$, disposición muy discutida en la doctrina por cuestiones como las

\footnotetext{
${ }^{20}$ Pergami, «L’appello...», cit., pág. 394.

${ }^{21}$ Así, Delmaire, «Largesses sacrées et res privata», cit., pág. I85; SPAGNUOLO VigoRITA, «Aspetti e problema del proceso fiscale», cit., pág. I52 nt. IO.

${ }^{22}$ Pergami, «L'appello...», cit., págs. 270 y ss.

${ }^{23}$ Así, Spagnuolo Vigorita, «Aspetti e problema del proceso fiscale», cit., pág. I6I.

${ }^{24}$ En el Código Teodosiano la constitución está fechada el iq de junio del 339 y en la inscriptio figura Constancio. Sin embargo, es generalizada la opinión de la doctrina en atribuir la autoría a Constantino el Grande, ya que el destinatario, Anicio Juliano, fue praefectus urbi entre los años 326 y 329, considerando como la mejor fecha la del 329. Así, MommSEn, «Theodosiani libri XVI», cit., pág. 629; CHASTAGnOL, «La préfecture urbaine a Rome sous le Bas-Empire», Paris, I960, pág. I3I; 384 nt. I; DuponT, «La procédure civile dans les constitutions de Constantin. Traits caractéristiques», en RIDA, 2I, I974, pág. I94 nt. I4; pág. I97 nt. 37; DE BonfiLs, «Prassi giudiziaria e legislazione nel IV secolo», Symm., rel. 33; en BIDR, 78, I975, pág. 306, nt. 44; Delmaire, «Largesses sacrées et res privata», cit., pág. 83; 86; Spagnuolo Vigorita, «Aspetti e problema del proceso fiscale», cit., I52 nt. IO; I6I y nt. 69; I63 nt. 8I; KASER, «Das römische ZivilprozessRecht», München, I996, pág. 53I nt. 47; 535 nt. 24; 537 nt. 44; 544 nt. I6; CUNEO, «La legislazione di Costantino II, Costanzo II e Constante (337-36I) », Milano, I997, pág. 48; 467; PERGAMI, «L’appello...», cit., pág. 88 nt. 73; 450 nt. I24; ID. «Appellatio more consultationis», cit., pág. I67 nts. 8 y 9; «Studi...», cit., pág. 26I nt. 8; 262 nt. 9; sin embargo,
} 
litterae dimissoriae, la jurisdicción del rationalis urbis Romae y los dos órganos encargados de conocer la apelación de sus sentencias, el praefectus urbi y el tribunal imperial, según se trate respectivamente de causas entre particulares o de causas fiscales, supuesto este último donde un sector de la doctrina ha creído encontrar la prueba de la innovación constantiniana de la apelación more consultationis, considerado por SPAGNUOLO VIGORITA ${ }^{25}$ como el instrumento usual de impugnación en materia fiscal con Constantino:

C. Th. II. 30. I8: Imp. Constantius A. Anicio Iuliano p(raefecto) u(rbi). Quotiens rationalis vel officii necessitate poscente vel ex praerogativa rescripti inter privatos iudicaverit, si a sententia fuerit provocatum, non ad nostram scientiam referendum est, sed apostolis datis, quod iuxta observatam rationem postulari sufficiet, ad auditorium gravitatis tuae, cui ad vicem nostram delata iudicatio est, partes pervenire oportet, in fiscalibus causis servato priscae consuetudinis more, ut opinione edita universa ad nostram scientiam referantur. Dat. XIII kal. Iul. Serdicae; $p($ ro)p(osita) vi kal. Aug. Rom(ae) Constantio A. II et Constante conss.

Lo primero que llama la atención es el singular supuesto contemplado en la epistula: la jurisdicción fiscal ejercida inter privatos por un funcionario de la administración financiera, el rationalis, actuación que puede deberse a - officii necessitate poscente - en el sentido atribuido por DeLAMIRE y PERGAMI ${ }^{26}$, no del ejercicio de la jurisdicción propia del funcionario en el ámbito de sus competencias, sino al contrario, una intervención extraordinaria y fuera de sus competencias normales motivada por una exigencia objetiva o por necesidad de su cargo, o bien -ex praerogativa rescripti-, esto es, porque le ha sido demandada, en el caso concreto, por un rescripto imperial. En tal caso, de la apelación conocerá el praefectus urbis Romae, destinatario de la disposición, cuya competencia viene calificada como - cui ad vicem nostram delata iudicatio est- ${ }^{27}$, con la remisión de los apostolis o littterae dimissoriae ${ }^{28}$. La constitución justifica este requisito aludiendo a una observata

en «Interesse pubblico e tutela del privato», cit., pág. 4I4, en «Centralismo e decentramento nell'attività giurisdizionale della tarda antichità», en Studi, cit., pág. 227, data la constitución en el 339. Cfr. PADOA SCHIOpPA, «Ricerche sull'appello», cit., pág. 20 nt. 26, la data en el 339, sin embargo en 27 y 69 nt. 88, la data en el 329. MASI, «Ricerche sulla res privata del Prínceps», Milano, I97I, pág. 84 y GoRIA, «La giustizia nell'Impero romano d'Oriente: organizzazione giudiziaria», en La giustizia nell'Alto Medioevo (secoli V-VIII) (Settimane di studio del Centro Italiano di Studi Sull'Alto Medioevo, 42, Spoleto, I995, pág. 283 nt. 7I, recogen las dos fechas. No se pronuncian, BASSANELLI, «La legislazione processuale di Giustino I (9 luglio 5I8 - I agosto 527», en SDHI, 37, I97I, pág. I72 nt. 57; GAUDEMET, «Constitutions constantiniennes relatives à l'appel», cit., pág. 73 nt. I66; VINCENTI, «Ante sententiam appellari potest», cit., pág. 83 nt. I44.

${ }^{25}$ Spagnuolo Vigorita, «Aspetti e problema del proceso fiscale», cit., pág. I6I.

${ }^{26}$ Delmaire, «Largesses sacrées et res privata», cit., pág. 202; PerGAMI, «L'appello...», cit., págs. II2 y ss..; 45I nt. I25; ID. «Appellatio more consultationis», cit., pág. I67; «Studi...», cit., págs. 26I y ss.

${ }^{27}$ Así, PAdOA SchiopPa, «Ricerche sull'appello», cit., pág. I8 nt. I8; BASSANELLI, «La legislazione processuale di Giustino I», cit., pág. I72; DUPONT, «La procédure civile dans les constitutions de Constantin», cit., págs. I93 y ss.; I97 nt. 37; Delmaire, «Largesses sacrées et res privata», cit., pág. 203; SPAGnuolo Vigorita, «Aspetti e problema del proceso fiscale», cit., pág. I6I. En opinión de VINCENTI, «Ante sententiam appellari potest», cit., pág. 83, competente para conocer la apelación es el comes rerum privatarum. Sobre la jurisdicción vice sacra, vid., PERGAMI, «L'appello...», cit., págs. 425 y ss., con un estado de la cuestión.

${ }^{28}$ Padoa Schioppa, «Ricerche sull'appello», cit., pág. 22 nt. 3I; Spagnuolo Vigorita, «Aspetti e problema del proceso fiscale», cit., págs. I6I y ss.; DELMAIRE, «Largesses sacrées et res privata», cit., pág. 203. 
ratio, según la cual se considera cumplido siempre que el apelante - partes $^{29}$ - haya solicitado al juez a quo dicho escrito de remisión o apóstoles.

Como ha observado PERGAMI ${ }^{30}$, la constitución alude a una observata ratio, sin precisar cuál sea. En su opinión, la misma se inspira en la praxis tardo clásica, recogida por Marciano en D. 49. 6. $\mathrm{I}^{3 \mathrm{I}}$, donde el jurista afirma que «después de interponerse la apelación, el juez contra el que se apela debe dirigir un escrito al juez que debe conocer en apelación, sea el príncipe o sea otro, el cual escrito se llama de remisión o apóstoles», continua el jurista afirmando que «basta haber pedido el escrito de remisión dentro del plazo, con insistencia y repetidas veces, para que, si no se cursa, se pueda apelar contra la negativa, pues las constituciones imperiales exigen la insistencia en el que solicita el escrito de remisión», prosigue el fragmento que «es justo, por lo tanto, que si el que debe expedir el escrito de remisión deja de hacerlo, no perjudique esto al solicitante». La constitución de Constantino se expresa casi con las mismas palabras utilizadas por Marciano -postulari sufficiet-, lo que lleva a pensar en una referencia buscada y conocida. El citado autor ha destacado ${ }^{32}$ como la disposición parece no conocer o no querer tener en cuenta la normativa dioclecianea, ya que ahora la petición de las litterae dimissoriae se considera como un acto de parte para dar impulso al procedimiento de apelación, frente a la regulación del edicto de Diocleciano del año 294 donde este acto se realizaba de oficio por el juez a quo aun cuando el apelante no lo hubiera solicitado -sine aliqua dilatione etiam non petente appellatore- ${ }^{33}$.

La disposición no precisa el plazo dentro del cual el apelante debe cumplir con su obligación de solicitar el escrito de remisión al juez a quo. Marciano tampoco indica plazo alguno - intra tempus-, por lo que quizá Constantino mantuviera vigente el plazo de cinco días recogido en las Sententiae de Paulo (V. 34. I) $)^{34}$. En cuanto al envío de las actuaciones al juez ad quem, como afirma PERGAMI ${ }^{35}$, corresponde su remisión al juez a quo.

\footnotetext{
${ }^{29}$ Pergami, L’appello...», cit., pág. 269 nt. 5 .

${ }^{30}$ Pergami, L’appello...», cit., pág. 88 s.; 387; ID., «Appellatio more consultationis», cit., pág. I68; Studi...», cit., pág. 262.

${ }^{31}$ D. 49. 6. I pr. (Marcianus, libro II de appellationibus): Post appellationem interpositam litterae dandae sunt ab eo, a quo appellatum est, ad eum, qui de appellatione cogniturus est, sive principem sive quem alium, quas litteras dimisorias sive apostolos appellant. I.- Sensus autem litterarum talis est: appellasse puta Lucium Titium a sententia illius, quae inter illos dicta est. 2.- Sufficit autem petiisse intra tempus dimisorias instanter et saepius, ut, et si non accipiat, id ipsum contestetur; nam instantiam repetentis dimisorias constitutiones desiderant. Aequum est igitur, si per eum steterit, qui debebat dare literas, quominus det, ne hoc accipienti noceat.
}

Sobre el texto, vid., por todos, Pergami, «L'appello...», cit., pág. 38; 89; 386 y nt. 26; ID., «Appellatio more consultationis», cit., pág. I68; «Studi...», cit., pág. 262.

${ }^{32}$ Pergami, «L'appello...», cit., págs. 50 y ss.; 89; 387; 40 I nt. 38.

${ }^{33}$ C. J. 7. 62. 6. 6 (Impp. Diocletianus et Maximianus AA. et CC dicunt). Apostolos post interpositam provocationem, etiam non petente appellatore, sine aliqua dilatione iudicem dare oportet cautione videlicet de exercenda provocatione in posterum minime praebenda.

${ }^{34}$ P. S. V. 34. I: Ab eo, qui appellatum est, ad eum, qui de appellatione cogniturus est, litterae dimissoriae diriguntur, quae vulgo apostoli appellantur: quorum postulatio et acceptio intra quintum diem ex officio facienda est. Sobre el tema, vid., PerGami, «L'appello...», cit., págs. 38 y ss.; 383 y ss.

${ }^{35}$ Pergami, «L'appello...», cit., pág. 40I nt. 38; ID., «Appellatio more consultationis», cit., pág. I68; «Studi...», cit., pág. 262. 
Respecto al contenido del escrito de remisión, la disposición guarda silencio; no obstante, quizá como los redactores teodosianos han tenido acceso al texto de Marciano, citado anteriormente, podría adoptar el contenido que dicho jurista nos proporciona cuando afirma que «el tenor de ese escrito es de que Lucio Ticio, por ejemplo, ha apelado contra la sentencia de tal juez que se dictó entre tal y cual litigante».

Después de analizar las cuestiones que presenta la disposición constantiniana de la apelación ante el praefectus urbis Romae de la sentencia inter privatos emitida por el rationalis urbis Romae, la epistula añade que si se trata de materia fiscal, competente para conocer la apelación de la sentencia emitida por el rationalis será el tribunal imperial - ad nostram scientiam-, según una priscae consuetudinis mos, acompañada de opinione edita universa ${ }^{36}$.

PERGAMI $^{37}$ ha analizado el sentido de la llamada a mos priscae consuetudinis, considerando que la cancillería constantiniana debía de referirse no a una norma escrita, sino a una praxis, y a una praxis tan antigua como para que pudiera ser calificada como prisca. Ello prueba que no existía hasta ese momento una expresa regulación de la materia, sino que venía regulada por una praxis consuetudinaria. El precedente de esta constitución, así como de otras, en las que se habla de opinio con relación a la apelación, podría estar, según el citado autor, en la opinio de la que trata Macro en D. $49 \cdot 5 \cdot 6^{38}$, donde el jurista afirma que «los mandatos imperiales disponen que el juez que no haya admitido la apelación, debe manifestar inmediatamente su opinión sobre el asunto, por medio de un comunicado, y la causa por la que no admitió la apelación, dando al litigante una copia del escrito». Dicho precedente habría inspirado a Constantino para extender a la apelación en general la normativa que el jurista constata para su época, y que en el siglo IV bien puede ser considerada como una prisca consuetudo. Respecto de la matización de Macro de que la obligación de expresar la opinio había sido impuesta por mandatos imperiales, considera Pergami que quizá la cancillería constantiniana haya conocido su existencia en la práctica, sin acudir a las fuentes normativas específicas, lo que explicaría la referencia a prisca consuetudo. Para Pergami, la conclusión es que quizá sin un preciso diseño, quizá interpretando ireflexivamente la normativa citada por Macro (junto a la de otros juristas cuyos escritos no nos han llegado, pero que los funcionarios de la cancillería imperial de comienzos del siglo IV bien habrían podido conocer), Constantino llega a generalizar la norma de que la apelación debe de ir acompañada de la opinio del juez y de las refutatoriae

${ }^{36}$ Spagnuolo Vigorita, «Aspetti e problema del proceso fiscale», cit., pág. I62, identifica la editio opinionis con la sentencia del juez. Cfr. Pergami, «L'appello...», cit., pág. 99 nt. 97; 442. Sobre las varias posiciones doctrinales mantenidas por los distintos autores, sobre distintas bases textuales, de la existencia de la appellatio per relationem o more consultationis, vid., por todos, PERGAMI, «L'appello...», cit., págs. 447 y ss.; ID. «Appellatio more consultationis», cit. págs. I65 y ss.; «Studi...», cit., págs. 259 y ss., con sus acertadas críticas.

${ }^{37}$ Pergami, «Interesse pubblico e tutela del privato», cit., págs. 4I4 y ss; «Studi...», cit., págs I96 y SS.; ID., «L’appello...», cit., pág. 5I, IOI y ss.; ID. «Appellatio more consultationis», cit. pág. I69; «Studi...», cit., pág. 263; ID. «La competenza giurisdizionale dell'imperatore», cit., pág. 422. Cfr. PADOA Schioppa, «Ricerche sull'appello», cit., pág. 22 nt. 3I; SPAGNUOLO VIGORITA, «Aspetti e problema del proceso fiscale», cit., I6I ss.

${ }^{38}$ D. 49. 5. 6 (Macer libro II de appellationibus): Sciendum est, cum appellatio non recipitur, praecipi sacris constitutionibus omnia in eodem statu esse nec quicquam novari, etiamsi contra fiscum appellatum sit: eumque, qui appellationem non receperit, opinionem suam confestim per relationem manifestare et causam, pro qua non recepit appellationem, eiusque exemplum litigatori edere debere mandatis cavetur. 
de las partes, regla que con anterioridad a él, Diocleciano había exigido para la apelación del proceso criminal. 